\title{
Development and Characterisation of a Smoking Behaviour Measurement System *
}

\author{
by Carl A. Vas ${ }^{1}$, Caner Ü. Yurteri ${ }^{1}$, Colin J. Dickens ${ }^{2}$, and Krishna Prasad ${ }^{1}$ \\ ${ }^{1}$ Group Research \& Development, British American Tobacco, Regents Park Road, Southampton SO15 8TL, UK \\ ${ }^{2}$ Present address: Nicoventures, Globe House, 4 Temple Place, London, WC2R 2PG, UK
}

\section{SUMMARY}

Respiratory deposition from smoking articles is influenced by particle or droplet properties (such as diameter), puffing parameters (such as draw effort or pressure drop, flow rate, duration), mouth losses, and post-puff inhalation dynamics (determined by inhalation depth, volume and breath hold duration). The Smoking Behaviour System (SBS) described herein is a novel system with regard to its capability to measure flow and duration characteristics of typical smoking cycles, which may consist of puffing, mouth hold, post-puff inhalation, breath hold and exhalation. It combines two analysers: the first measures the puffing topography and optical obscuration from puffed aerosol, while the second measures the respiratory topography and optical obscuration from exhaled aerosol. The puffing and respiratory analysers were calibrated and operated between flow rates of 0-7 L.min ${ }^{-1}$ and $0-50$ L. $\mathrm{min}^{-1}$, respectively, as typically encountered during the human smoking cycle. The volumes measured by the puffing and respiratory analysers met the design specification and tolerance limits of $\pm 2 \%$ and $\pm 5 \%$, respectively. The optical obscuration measurements showed no statistical difference among the three units tested or in day-to-day variation, verifying the robustness of the SBS for use in optical measurements of smoke when combined with topography measurements. In conclusion, the SBS is a validated technology that provides a means to measure the real-time flow and duration profile of puffing, mouth hold, post-puff inhalation, breath hold and exhalation topography, thereby capturing the complete smoking cycle at a $25-\mathrm{Hz}$ resolution. Furthermore, the SBS is distinguished from typical puff or respiratory profilers by providing real-time puffed and exhaled optical obscuration measurement of the aerosol, and thus an indirect quantification of "tar" from puffed cigarette smoke and exhaled smoke. [Beitr. Tabakforsch. Int. 26 (2015) 219-231]

KEYWORDS: Smoking behaviour system, puffing topography, respiratory topography, optical obscuration.

\section{ZUSAMMENFASSUNG}

Die respiratorische Ablagerung aus Tabakwaren wird beeinflusst durch die Eigenschaften der Teilchen oder Tröpfchen (wie Durchmesser), Zugparameter (wie Zugaufwand oder Zugwiderstand, Flussrate, Dauer), Mundverluste und Inhalationsdynamik nach dem Zug (ermittelt durch Inhalationstiefe, -volumen und Atemanhaltezeit). Das hier beschriebene Smoking Behaviour System (SBS) ist ein neues System hinsichtlich seiner Fähigkeit zur Messung von Fluss- und Dauereigenschaften typischer Rauchzyklen, die aus Ziehen, Im-Mund-Halten, Einatmen nach dem Zug, Atemanhalten und Ausatmen bestehen können. Dabei werden zwei Analysegeräte kombiniert. Das erste misst die Zugtopographie und optische Verdunklung durch eingeatmetes Aerosol, während das zweite die Atemtopographie 
und optische Verdunkelung durch ausgeatmetes Aerosol misst. Die Zug- und Atem-Analysegeräte wurden kalibriert und jeweils mit Flussraten von 0-7 L/min und 0-50 L/min betrieben, wie es typischerweise beim menschlichen Rauchzyklus der Fall ist. Die durch die Zug- und AtemAnalysegeräte gemessenen Volumina erfüllten die Designspezifikation und Toleranzgrenzen von $\pm 2 \%$ bzw. $\pm 5 \%$. Die Messungen der optischen Verdunkelung ergaben keinen statistischen Unterschied zwischen den drei getesteten Einheiten oder der täglichen Variation. Dadurch wurde die Robustheit des SBS zur Verwendung in optischen Rauchmessungen in Kombination mit Topographiemessungen nachgewiesen. Fazit: Das SBS ist eine validierte Technologie, die eine Möglichkeit zur Messung der Echtzeitströmung und des Dauerprofils der Topographie beim Ziehen, Im-Mund-Halten, Einatmen nach dem Zug, Atemanhalten und Ausatmen bietet, wodurch der gesamte Rauchzyklus mit einer 25-Hz-Auflösung erfasst wurde. Des Weiteren unterscheidet sich das SBS von typischen Zugoder Atemprofilern darin, dass es eine Echtzeitmessung der optischen Verdunkelung durch eingeatmetes und ausgeatmetes Aerosol und damit eine indirekte Quantifizierung des Teers aus eingeatmetem Zigarettenrauch und ausgeatmetem Rauch bietet. [Beitr. Tabakforsch. Int. 26 (2015) 219-231]

\section{RESUME}

Les dépôts sur les voies respiratoires laissés par les articles de tabac sont conditionnés par les propriétés des particules ou des gouttelettes (telles que le diamètre), les paramètres des bouffées (tels que l'effort de tirage ou la perte de charge, la vitesse de filtration, la durée), les pertes en bouche et la dynamique d'inhalation post-bouffée (déterminée par la profondeur d'inhalation, le volume d'inhalation et la durée de l'apnée). Le système de comportement tabagique (SBS) décrit dans le présent article est un système inédit en raison de sa capacité à mesurer les caractéristiques de filtration et de durée de cycles tabagiques typiques, qui peuvent se composer d'une bouffée, une retenue intrabuccale, une inhalation post-bouffée, une apnée et une expiration. Le présent système combine deux analyseurs : Le premier mesure la topographie des bouffées et l'obscurcissement optique causé par l'aérosol ingéré par bouffée tandis que le second mesure la topographie respiratoire et l'obscurcissement optique causé par l'aérosol expiré. Les analyseurs de respiration et de bouffée furent calibrés et utilisés à des vitesses de filtration oscillant respectivement entre $0-7 \mathrm{~L} \cdot \mathrm{min}^{-1}$ et $0-50 \mathrm{~L} \cdot \mathrm{min}^{-1}$ et similaires à celles typiquement observées durant le cycle tabagique humain. Les volumes mesurés par les analyseurs de respiration et de bouffée furent conformes aux spécifications de conception et aux seuils de tolérance fixés respectivement à $\pm 2 \%$ et $\pm 5 \%$. Les mesures de l'obscurcissement optique ne révélèrent ni différence statistique entre les trois unités testées ni variation au jour le jour, confirmant la fiabilité du SBS pour les mesures optiques de la fumée lorsqu'il est combiné avec des mesures topographiques. En conclusion, le SBS est une technologie validée qui propose un outil capable de mesurer le profil de durée et de vitesse de filtration en temps réel de la topographie de la bouffée, de la retenue intrabuccale, de l'inhalation post-bouffée, de l'apnée et de l'expiration et donc de faire une capture du cycle tabagique complet à une résolution de $25 \mathrm{~Hz}$. Par ailleurs, le SBS se distingue des outils traditionnels de profilage de la respiration et de la bouffée en apportant des mesures en temps réel de l'obscurcissement optique lors de la bouffée et de l'expiration de l'aérosol et donc une quantification indirecte du goudron contenu dans la fumée de cigarette inhalée en bouffée et de la fumée expirée. [Beitr. Tabakforsch. Int. 26 (2015) 219-231]

\section{INTRODUCTION}

Parameters such as puff flow rate, duration, mouth hold time, subsequent inhalation and exhalation volumes, flow rates and breath hold time affect the amount of smoke delivered to the mouth, and influence respiratory deposition and lung dose from the tobacco smoke aerosol. These parameters vary depending on age, gender, lung morphology, function and respiratory health. Breathing patterns affect the inhaled particle dynamics and influence the respiratory deposition. Whereas a natural tidal breathing pattern includes inhalation, exhalation and pause stages at regular frequencies, alternative breathing patterns may change deposition when particles are delivered from various medical and aerosol-producing devices. Breathing patterns can be fast, slow, deep or shallow and this will affect inhalation flow rates.

In general, particle deposition also depends on particle size. The particle size of therapeutic aerosols typically ranges from 1 to $10 \mu \mathrm{m}$ in mass median aerodynamic diameter $(1,2)$. Cigarette smoke particles are generally smaller, being approximately 50 to $400 \mathrm{~nm}$ (3). Particles above $1000 \mathrm{~nm}$ are mainly deposited by impaction, whereas smaller particles $(<50 \mathrm{~nm})$ are deposited by diffusion (Brownian motion). Deposition of particles in the range $50-1000 \mathrm{~nm}$ occurs predominantly by sedimentation and is generally inefficient. Low flow breathing patterns thus facilitate diffusional deposition and sedimentation, whereas higher flow breathing can increase impaction $(4,5)$. In addition, any breath hold will effectively increase the deposition of cigarette smoke particles in pulmonary airways by sedimentation.

In the case of cigarette smoking, the typical human smoking cycle includes distinct physical activities. Initially, smokers puff on a cigarette and the smoke is drawn into the mouth, where it may be held for a short period of time in a step commonly referred to as "mouth hold". After the puff, the smoking article is removed from the lips, often allowing some of the undiluted smoke to escape. In addition, some or all of the undiluted smoke can be spilled out or even blown from the mouth prior to inhalation - an activity referred to as "mouth spill". However, many smokers go on to inhale the smoke, where they draw the puffed smoke into their lungs. This step requires diluting ambient air to be drawn into the respiratory tract. Finally, at the end of the inhalation phase, a small breath hold may occur, after which the smoker exhales the smoke before resuming normal tidal breathing $(3,6-8)$.

Historically, puffing behaviour studies have been limited to the first phase of the smoking cycle, evaluating puffing topography using devices encompassing differential 
pressure measurements. One example is the Smoking Analyser 7 (SA7) - an instrument developed at British American Tobacco GR\&D in conjunction with Schneider Electric Ltd. (formerly C-Matic Ltd., UK) (9). A second example is the desktop Clinical Research Support System (CReSS), also known as the portable CReSSmicro - an instrument developed by Plowshare Technologies (Baltimore, MD, USA), and later acquired and commercialised by Borgwaldt KC (Hamburg, Germany) as CReSSpocket. The CReSSmicro device has been used globally to record the puffing topography of smokers in various studies on, for example, quantification of mouth level exposure and validity for clinical use (10-18).

Since the 1970s, many studies have measured the inhalation patterns of smokers using cigarettes of differing "tar" and nicotine yields (19-33), as reviewed by BERNSTEIN (19) and ST. CHARLES et al. (20). Among various methods such as impedance pneumography, mercury strain gauge, transthoracic impedance and inhalation index, the majority of studies have used respiratory inductive plethysmography - a technique that measures inhalation patterns noninvasively, including post-puff inhalation volume and duration, exhalation volume and duration, and tidal volume. As summarised by BERNSTEIN (19), smokers are reported to inhale smoke to approximately $25 \%$ of vital capacity, which is higher than typical tidal breathing of $15 \%$ vital capacity. A similar conclusion was also drawn by ST. CHARLES et al. (20).

Machine smoking regimes such as ISO and Health Canada Intense are not representative of typical smoking behaviours and do not reflect possible variation found between smokers (34). Therefore, understanding smoking behaviour is essential knowledge to understanding smokers' exposure. A number of studies have measured either puffing topography or inhalation topography, but none has measured them together using a single system (10-33).

Previously, LifeShirt ${ }^{\circledR}$ technology (VivoMetrics, Ventura, CA, USA) has been used as a spirometer (for inhalation and exhalation flow measurements) alongside the SA7 puffing topography device to measure the complete smoking behaviour cycle (puffing and respiratory topography) (35). However, this combined puffing and respiratory device can be invasive and can hinder the smoker from smoking in a natural manner.

To minimise the influence of test equipment on smokers' behaviour, the aim of the present study was to develop a system that incorporates the puffing and respiratory topography devices into one small, portable, and easy-touse unit. The resulting Smoking Behaviour System (SBS; developed at British American Tobacco GR\&D in conjunction with Schneider Electric Ltd.; formerly C-Matic Ltd., UK) enables the measurement and recording of puff frequency, puff duration, puff flow rate, mouth and breath hold durations, as well as the post-puff inhalation and exhalation flow rates and durations, in real time. These measurements have the advantage of being time-aligned such that each one can be considered either in isolation or as part of the whole smoking cycle. These variables are key inputs in modelling the deposition of smoke aerosols in the human respiratory tract. To our knowledge, the SBS is the first of its kind with regard to its capability to capture the complete smoking cycle of puffing and respiratory topo- graphy. Herein, we describe its development and basic principle of operation, in addition to characterising the complete smoking cycle using the SBS. The SBS has been calibrated for flow rate and optical obscuration, and validated in terms of system-to-system and day-to-day variation in volume and optical obscuration measurements of smoke.

\section{METHODOLOGY}

The SBS comprises of four main components: a puffing mouthpiece (puffing analyser), respiratory mouthpiece (respiratory analyser), data acquisition transfer unit and heater unit (Figure 1).

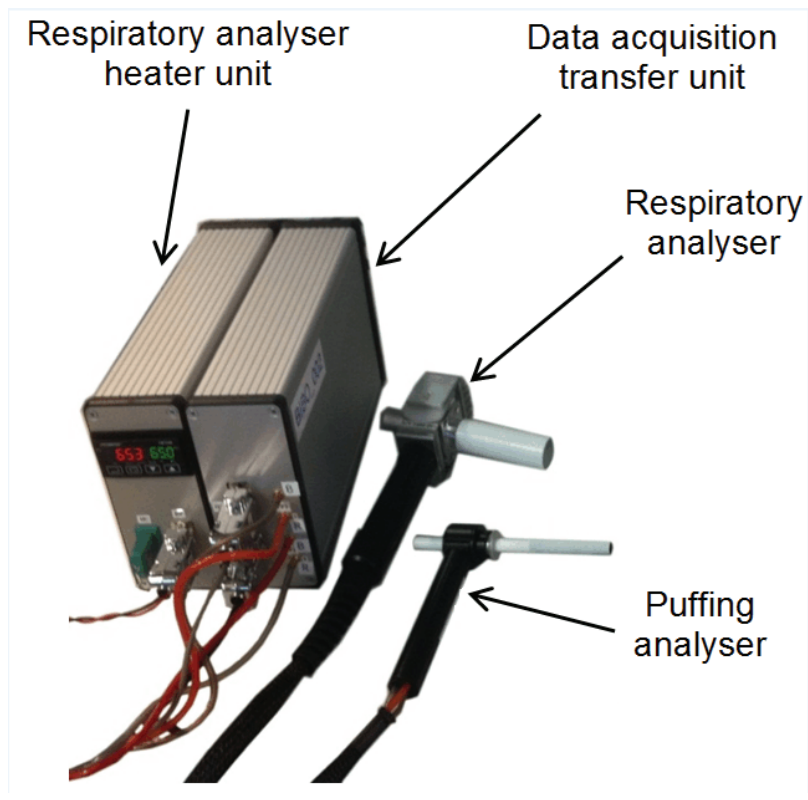

Figure 1. Smoking Behaviour System (SBS).

The puffing analyser consists of a cigarette holder with a unidirectional pressure transducer, light emitting diode (LED) (wavelength $660 \mathrm{~nm}$ ) and photo-detector. The latter two are mounted opposite each other, across the orifice of the module. Figure $2 \mathrm{~A}$ shows the internal dimensions of the puffing analyser (9). The pressure transducer will detect a pressure change across an orifice $(2 \mathrm{~mm})$, which is proportional to the square of the flow rate. As smoke is drawn through the puffing analyser, it passes between the LED and the photo-detector. The aerosol of the smoke obscures the light produced by the LED, causing a puffed optical obscuration signal on the photo-detector. This obscuration may be directly related to the quantity of smoke aerosol. An accurate estimation is possible via a correlation between the optical obscuration data and the respond characteristics of a particular cigarette smoke.

In general, aerosol characteristics include particle size and distribution, particle concentration and degree of dispersion, and refractive index. The optical obscuration also varies with the mass flux or transport rate of the particles 
and spacing between the LED and photo-detector. As flow rate and obscuration are measured simultaneously, optical obscuration rate can be obtained by multiplying these values, leading to an estimate of total obscuration for a given volume.

The respiratory analyser is similar in design to the puffing analyser of the SBS, but has an internal mouthpiece bore of $14 \mathrm{~mm}$ and contains a bidirectional pressure transducer that detects both positive and negative pressure change across a larger orifice $(10 \mathrm{~mm})$ to accommodate the higher flow rates (to derive the volumes inhaled and exhaled). Figure 2B shows the internal dimensions of the respiratory analyser. The respiratory analyser is heated to $65{ }^{\circ} \mathrm{C}$ to prevent condensation of water from the smoker's breath on the optics of the LED and photo-detector. Such condensation would interfere with the exhaled optical obscuration signal. The temperature of the respiratory analyser is measured and monitored by a thermocouple embedded in the body of the analyser.

The major advantage of using the SBS technology and measurement principle is that it provides a real-time profile of the flow and duration of puffing, post-puff inhalation and exhalation topography, thereby capturing the complete smoking behaviour cycle at a resolution of $25-\mathrm{Hz}$ (Figure 3).
(A)

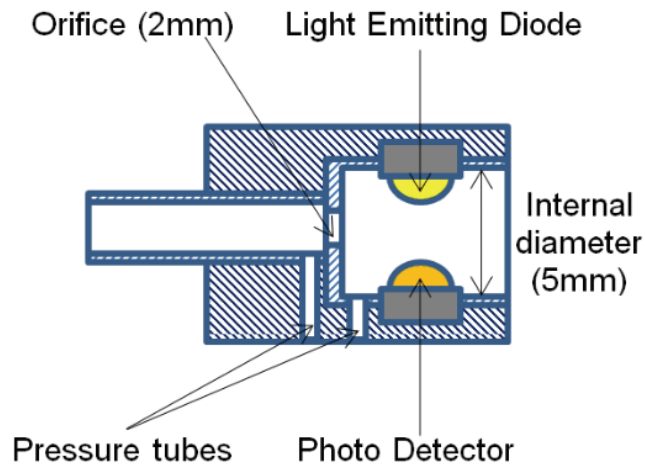

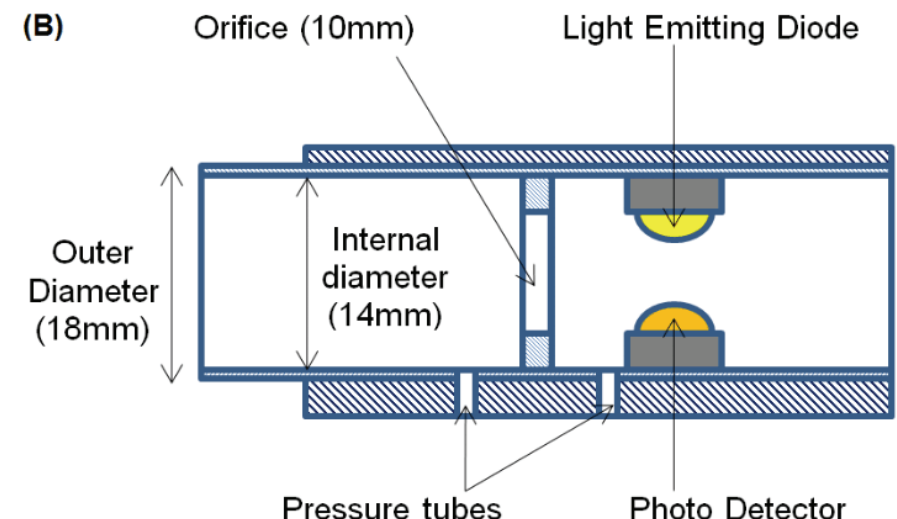

Pressure tubes

Photo Detector

Figure 2. Internal dimensions of the puffing analyser (A) and respiratory analyser (B).

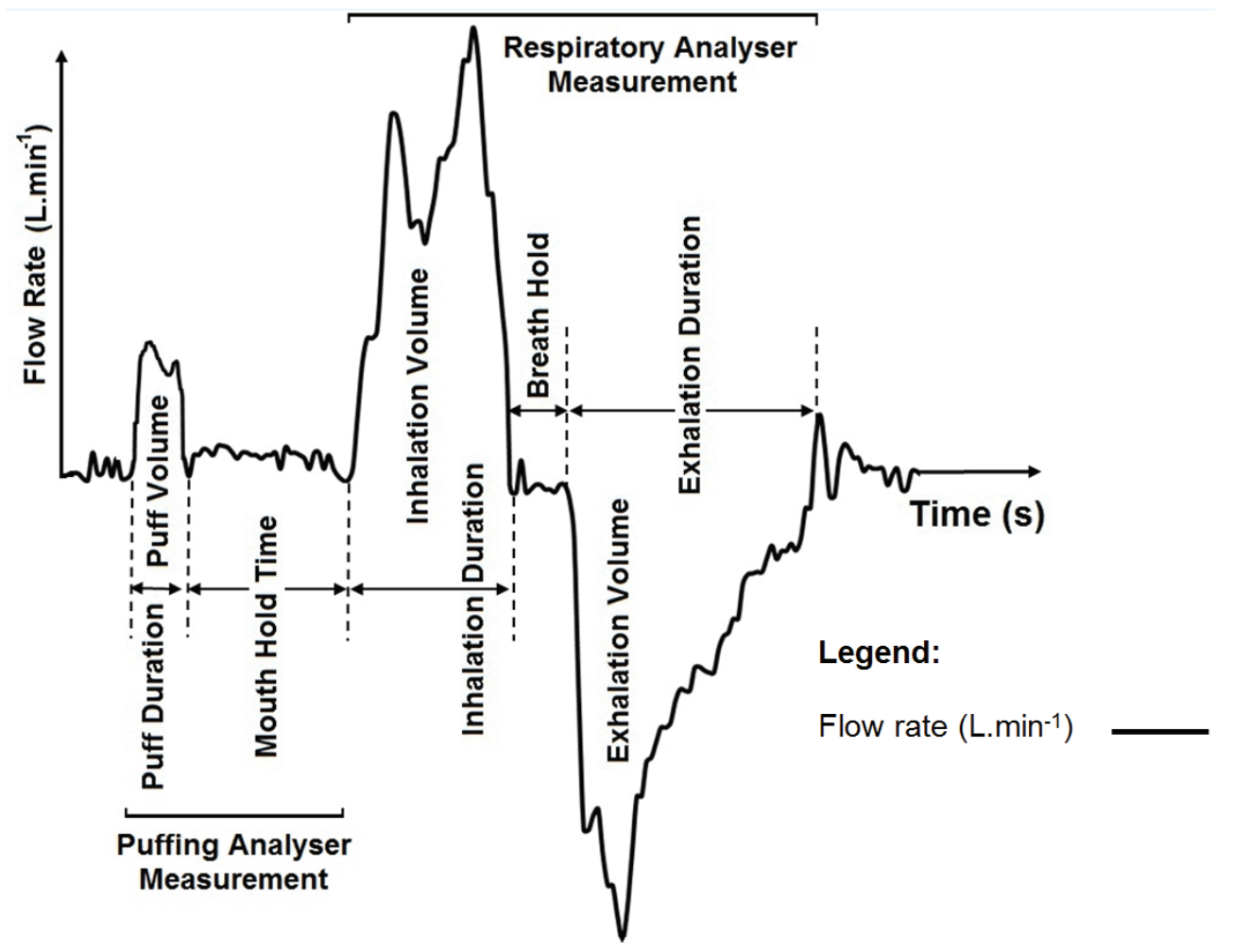

Figure 3. Smoker's real-time flow and duration profile of puffing, post-puff inhalation, and exhalation topography that captures the complete smoking behaviour cycle at $25-\mathrm{Hz}$ resolution using the SBS. 


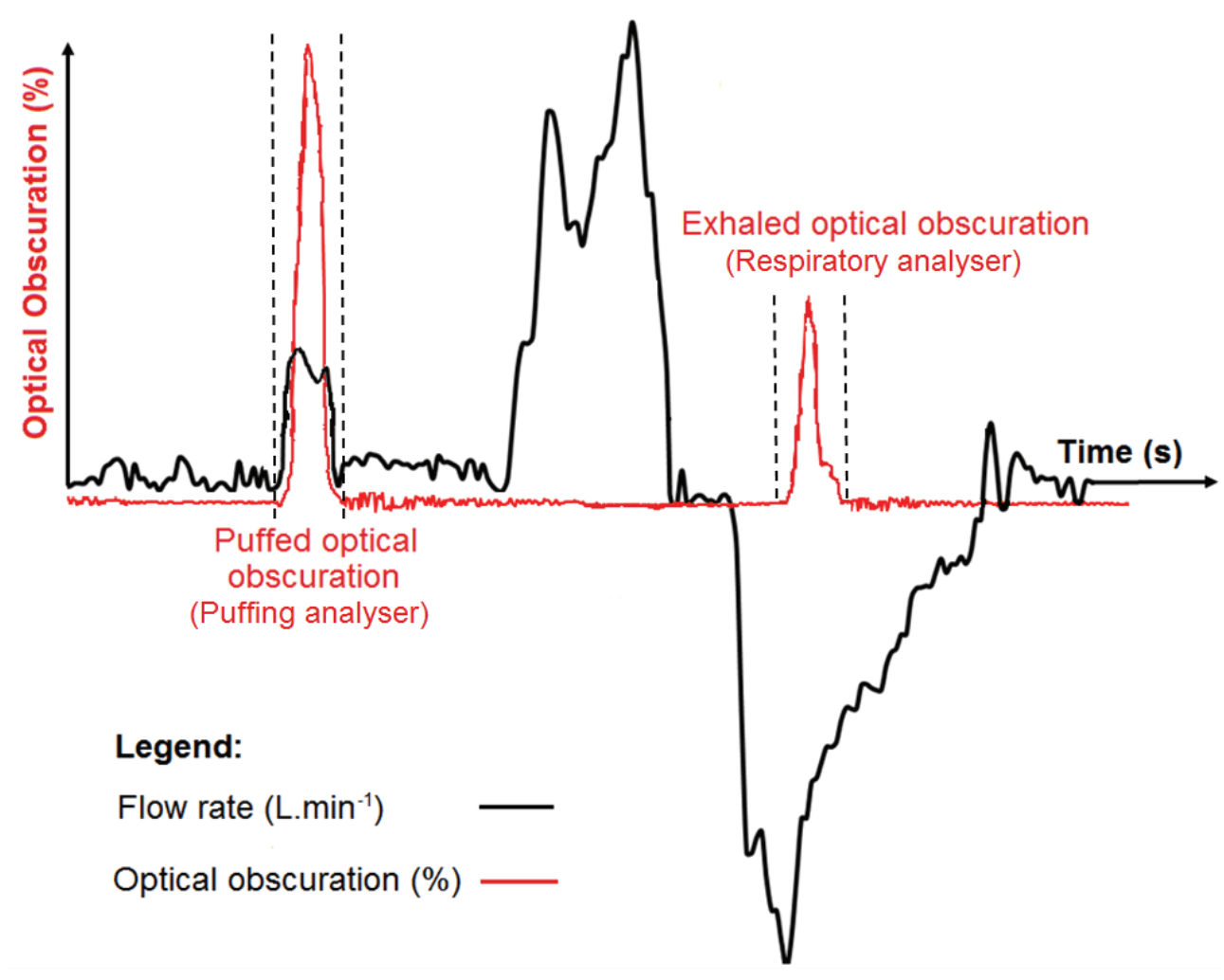

Figure 4. Smoker's real-time puffed and exhaled optical obscuration of aerosol captured during a typical smoking behaviour cycle at $25-\mathrm{Hz}$ resolution using the SBS.

In addition, the SBS provides a real-time puffed and exhaled optical obscuration measurement of the aerosol (Figure 4). Three SBS units were used throughout the calibration and validation testing to provide a measurement of intermediate repeatability.

\section{Pre-use flow calibration of the SBS}

The puffing analyser of the SBS was calibrated against set flow rates by connecting it in series to a Mass Flow Controller (MFC) (Omega, Manchester, UK, model number FMA-2612A) with an operating range of 0-100 L.min ${ }^{-1}$ and a vacuum pump (Bacca Air Technology Co Ltd. Taichung, Taiwan, model number VRT 425). The flow rate was set to 0 L.min ${ }^{-1}$ with data logging initiated within the SBS software, and allowed to stabilise for a period of $60 \mathrm{~s}$. The flow rate was then increased to $1 \mathrm{~L} \cdot \mathrm{min}^{-1}$, and further stabilised for $60 \mathrm{~s}$. This procedure was repeated from 2 to 7 L. min $^{-1}$ and then carried out in reverse from 7 to 0 L. $\min ^{-1}$, after which the data logging was stopped. The respiratory analyser of the SBS was calibrated for flow rate by following the same procedure, but at higher flow rates. The MFC was used to set flow rates between 0 and $50 \mathrm{~L} \cdot \mathrm{min}^{-1}$ in increments and decrements of $10 \mathrm{~L} \cdot \mathrm{min}^{-1}$. This procedure was performed on three SBS units because each unit has different calibration factors, owing to slight variations in manufacturing tolerances of the orifice. The range of flow rates tested by the puffing and respiratory analysers of the SBS reflects flow rates that are typically encountered during human smoking (34).

\section{Volume validation measurements of the SBS}

The volume validation measurements of the SBS were performed using calibrated gas syringes (Hans Rudolph Inc., Shawnee, KS, USA, Series 5530 \& 5550). The puffing analyser of the SBS was attached in-line with a $500-\mathrm{mL}$ calibrated gas syringe. Five $500-\mathrm{mL}$ puff volumes were passed through the unidirectional pressure transducer of the puffing analyser to produce one record, which was repeated three times a day for each of the three SBS units over a period of five days. The respiratory analyser of the SBS followed a similar procedure; however, a 3-L calibrated gas syringe was used and attached in-line to the respiratory analyser. Five inhalation and five exhalation volumes of 3-L were passed through the bidirectional pressure transducer of the respiratory analyser to produce one record, which was repeated three times a day over a period of five days for each of the three SBS units.

Optical obscuration calibration of the puffing analyser of the $S B S$

The puffing analyser of the SBS was calibrated by smoking commercial test cigarettes (ISO $7 \mathrm{mg}$ "tar") at four smoking regimes, consisting of eight puffs with a 2-s puff duration and a 30 -s puff frequency at puff volumes of 20 , 40, 60 and $80 \mathrm{~mL}$, respectively. The regimes were used to generate different levels of total particulate matter (TPM). The TPM is defined as the weight of smoke aerosol 
collected on a Cambridge filter pad (CFP) during machine smoking (36). A pre-weighed 44-mm CFP was placed inside the pad holder of an A14 smoking syringe driver (Borgwaldt KC, Germany), with the puffing analyser placed in-line with the pad holder. The test cigarette was then placed in the puffing analyser of the SBS and smoked at the required calibration regime. The TPM collected on the CFP was extracted with $20 \mathrm{~mL}$ of solvent and analysed by high-performance liquid chromatography for solanesol as a tobacco-specific marker of smoke particulate phase (37).

The puffed optical obscuration signal is a composite of measured flow rate and obscuration signal as described in the Methodology section. Using a Microsoft Excel ${ }^{\mathrm{TM}}$ macro, flow rate and obscuration signal per time step were multiplied and integrated over time to estimate the puffed optical obscuration. The puffed optical obscuration signal from the puffing analyser of the SBS was compared with the TPM collected on the CFP generated at each calibration regime. Three replicates of each regime were performed to build up a calibration curve of puffed optical obscuration versus TPM. The puffed optical obscuration signal was corrected for the "dead" volume, which is defined as the smoke aerosol that has passed through the optical region of the puffing analyser and has been registered by the optical sensors, but does not reach the CFP. The volume lost in the puffing analyser and CFP holder (dead volume $7.50 \mathrm{~mL}$ ) was subtracted from the total puff volume and divided by the total puff volume. The puffed optical obscuration signal (POOS) from the puffing analyser was multiplied by this correction factor [equation 1]:

$$
\text { POOS }(\% \text { obscuration } \mathrm{mL})=\frac{(\mathrm{TPV}-\mathrm{DV}) \times \mathrm{OO}}{\mathrm{TPV}}
$$

where POOS is the corrected puffed optical obscuration signal (\% obscuration $\mathrm{mL}), \mathrm{TPV}$ is the total puff volume
$(\mathrm{mL}), \mathrm{DV}$ is the dead volume lost in the puffing analyser and CFP holder $(\mathrm{mL})$, and $\mathrm{OO}$ is the puffed optical obscuration signal from the puffing analyser (\% obscuration $\mathrm{mL}$ ).

The corrected puffed optical obscuration signal was then calibrated to the amount of TPM that reached the CFP. The solanesol measured on the CFP was plotted against TPM to build up a second calibration curve. The corrected puffed optical obscuration signal was converted into puffed optical "tar". This was done by multiplying the calibration factor from the puffed optical obscuration signal versus TPM (using the calibration curve gradient).

\section{Optical obscuration calibration of the respiratory analyser of the SBS}

The respiratory analyser of the SBS was calibrated by smoking commercial test cigarettes (ISO $7 \mathrm{mg}$ "tar") at four smoking regimes, consisting of eight puffs with a 2-s puff duration, a 2 -s mouth hold and a 30 -s puff frequency, at puff volumes of 20, 40,60 and $80 \mathrm{~mL}$ respectively. The regimes were used to generate different levels of exhaled total particulate matter (ETPM), which is defined as the particulate matter exhaled from the simulation system and trapped onto a CFP.

Test cigarettes were smoked at the required regime using a smoke engine, which simulates puffing, inhalation and exhalation (Cambustion Ltd., Cambridge, UK), in combination with an anatomically correct mouth cast $(38,39)$. The smoke was puffed from the cigarette at the required regime into the mouth cast, held for $2 \mathrm{~s}$ to reflect the mouth hold action, and subsequently exhaled using $2.5 \mathrm{~L}$ of air over a 5 -s duration through the respiratory analyser of the SBS, to produce an exhaled optical obscuration signal. An exhaled breath sampling system and an external vacuum pump were used to capture the ETPM onto a 92-mm CFP (Figure 5) (40).

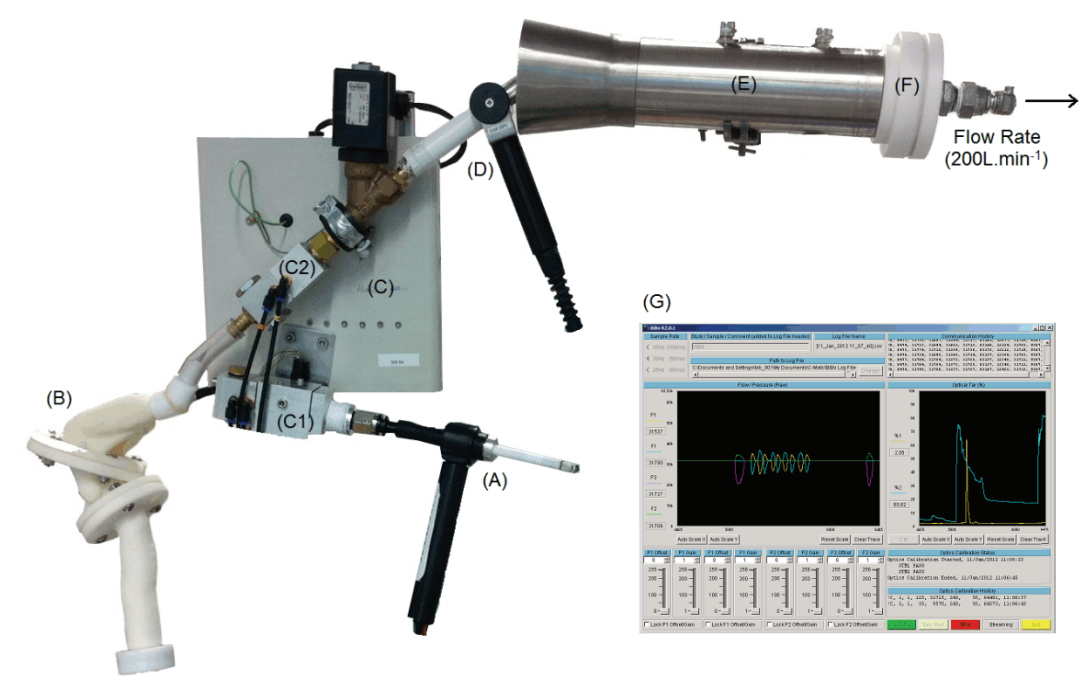

Figure 5. Experimental set-up for the exhaled optical obscuration calibration of the respiratory analyser of the SBS. (A) Puffing analyser (with cigarette in-line); (B) anatomically correct mouth cast; (C) puffing, inhalation and exhalation simulator; (C1) puffing simulator; (C2) inhalation and exhalation simulator; (D) respiratory analyser; (E) exhaled breath sampling system; (F) Cambridge filter pad holder; (G) real-time screen capture using the SBS. 
The high flow rates through the exhaled breath sampling system (200 L. $\left.\mathrm{min}^{-1}\right)$ used to draw and capture the exhaled total particulate matter (ETPM) onto the CFP are known to result in the loss of semi-volatile components of the ETPM, for example, nicotine, collected on the CFP (unpublished data). Therefore, the mass of ETPM cannot be measured gravimetrically and must be derived. However, solanesol $\left(\mathrm{C}_{45} \mathrm{H}_{74} \mathrm{O}\right)$ is a hydrophobic, non-volatile, long carbon chain isoprenoid alcohol with a calculated boiling point of $685.6 \pm 24{ }^{\circ} \mathrm{C}(6,41)$ and regarded as a tobacco-specific marker of smoke particulate phase (37). The vapour pressure of solanesol has been calculated by ST. CHARLES et al. (20) as $10^{-15} \mathrm{~Pa}$ via the SIMPOL.1 method (42), and $10^{-19} \mathrm{~Pa}$ via Chemspider (predicted/ACD Labs tab) (43). This very low vapour pressure suggests that there should be minimal evaporation of solanesol under the high flow rates used.

The estimated mass of the ETPM was derived from the measurement of solanesol from the CFP, using the ratio of solanesol measured on the CFP to TPM from the puffed optical obscuration calibration of the puffing analyser described in the previous section. Three replicates of each smoke regime were completed in order to produce a calibration curve of exhaled optical obscuration signal versus the derived ETPM.

\section{Optical obscuration validation of the $S B S$}

Three SBS units were used to carry out the optical obscuration validation measurements with commercial test cigarettes (ISO $7 \mathrm{mg}$ "tar"). The validation consisted of measuring the day-to-day and unit-to-unit variability of the puffed and exhaled optical obscuration measured by the puffing and respiratory analysers of the SBS. The experimental set up was identical to the exhaled optical obscuration calibration of the respiratory analyser (Figure 5).

The test cigarette was placed in the puffing analyser to measure the puffed optical obscuration and smoked using the puffing, inhalation and exhalation simulator under a defined regime of six puffs consisting of a $65-\mathrm{mL}$ puff volume, a 2 -s puff duration and a 30 -s puff interval. This regime was chosen to represent a more intense smoke regime as compared with the ISO standard. The smoke was puffed into an anatomically correct mouth cast, held for $2 \mathrm{~s}$ to reflect the mouth hold, and subsequently exhaled through the respiratory analyser continuously for $5 \mathrm{~s}$ using $2.5 \mathrm{~L}$ of air to record the exhaled optical obscuration. The validation measurements were performed twice a day on three SBS units in a randomised order over a period of 5 days.

\section{RESULTS AND DISCUSSION}

\section{Flow calibration results - puffing analyser}

A linear regression was applied to the data obtained from the puffing analyser flow calibration experiments. The square root of the measured differential pressure (DP) was plotted against the set flow rate controlled by the MFC. The square root of the measured DP was recorded in arbitrary units (a.u.) and flow rate in L.min ${ }^{-1}$. Figure 6 depicts the linear relationship for the puffing analysers of the three SBS units.
The model based on the linear regression was valid for the range of puff flow rates that are typically encountered during human smoking. The slope of the linear regression (calibration parameter) was determined for each puffing analyser for each SBS unit (Figure 6). A Microsoft Excel ${ }^{\mathrm{TM}}$ macro was used to convert the measured DP into flow rate, using the calibration parameters obtained from the linear regression, to validate the volume measurements. There were no significant differences in the calibration parameters among the puffing analysers of the three SBS units.

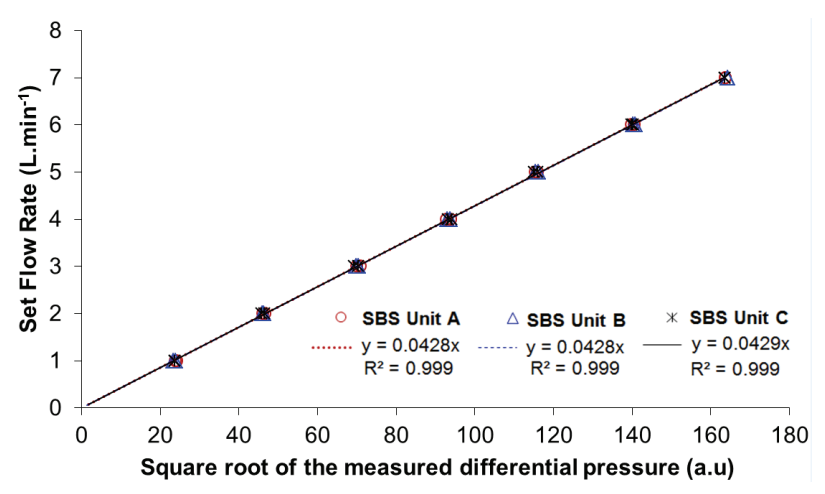

Figure 6. Flow calibration of the puffing analysers of the three SBS units, showing the set flow rates plotted against the square root of the measured differential pressure (DP).

\section{Flow calibration results - respiratory analyser}

The respiratory analyser flow calibration also produced a linear relationship between the set flows rates controlled by the MFC and the square root of the measured DP (Figure 7). The relationship shown was valid for the range of inhalation and exhalation flows encountered during human smoking. The flow calibration parameters were determined for each respiratory analyser for the three SBS units from the slope of the linear regression (calibration parameter) in Figure 7. These parameters were applied to a Microsoft ExcelTM macro to convert the measured DP from the respiratory analyser into flow rate, to be used in the volume validation measurements.

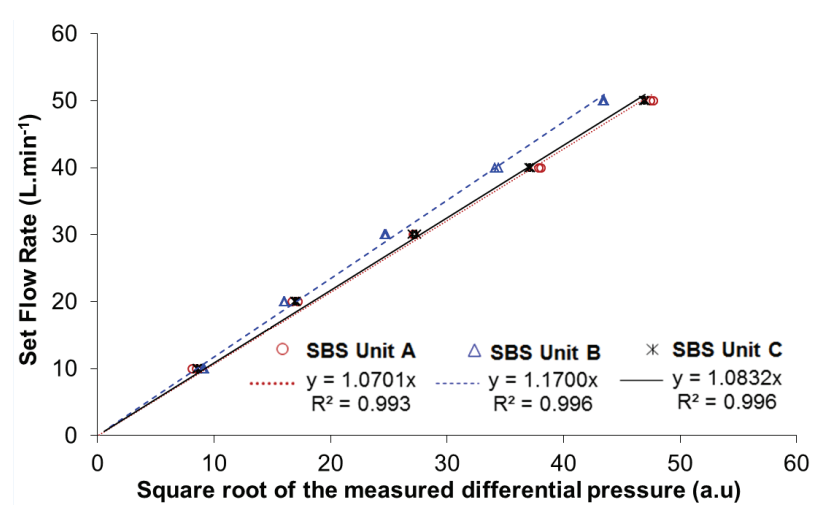

Figure 7. Flow calibration of the respiratory analysers of the three SBS units, showing the set flow rates plotted against the square root of the measured differential pressure (DP). 
Due to slight variations in the manufacturing tolerances of the $10-\mathrm{mm}$ orifice in the respiratory analyser, there were differences in the calibration parameters among the respiratory analysers of the SBS units.

\section{Volume validation results}

The mean and standard deviation (SD) values for the 500$\mathrm{mL}$ puff volume measured by each puffing analyser for each of the three SBS units over the five days are reported in Table 1. Analysis of variance (ANOVA) was used to evaluate the day-to-day and unit-to-unit effect on the puff volumes measured. There were no significant differences among the puffing analysers of the SBS units $(P=0.366)$, but there was a significant day-to-day effect $(P<0.001)$, driven by the tight precision of the measurement system. However, the data met the design specification and tolerance limit of $500 \mathrm{~mL} \pm 2 \%$ that was set for puff volume, and were consistent and reproducible throughout the duration of testing.

The mean \pm SD values for the 3-L inhaled and exhaled volumes measured by the respiratory analyser for each of the three SBS units over the five days are also reported in
Table 1. ANOVA was used to assess the day-to-day and unit-to-unit effect on the inhaled and exhaled volumes. There was no significant day-to-day effect on either the inhaled or the exhaled volumes measured $(P=0.239$ and $P=0.549$, respectively). There was no significant difference in inhaled volumes measured by the respiratory analysers of the SBS units $(P=0.183)$, although there was a significant difference in the exhaled volumes $(P=0.016)$. However, the exhaled volumes measured using the respiratory analyser of the SBS met the design specification and tolerance limit of $3 \mathrm{~L} \pm 5 \%$ that was set, and were consistent and reproducible throughout the duration of testing.

\section{Optical obscuration calibration results}

The LED and photo-detector within the puffing and respiratory analysers are used to measure the percentage of light obscuration from aerosols. Optical obscuration signals from the puffing and respiratory analysers are calibrated against different delivery levels of TPM. The calibration procedure is outlined schematically in Figure 8.

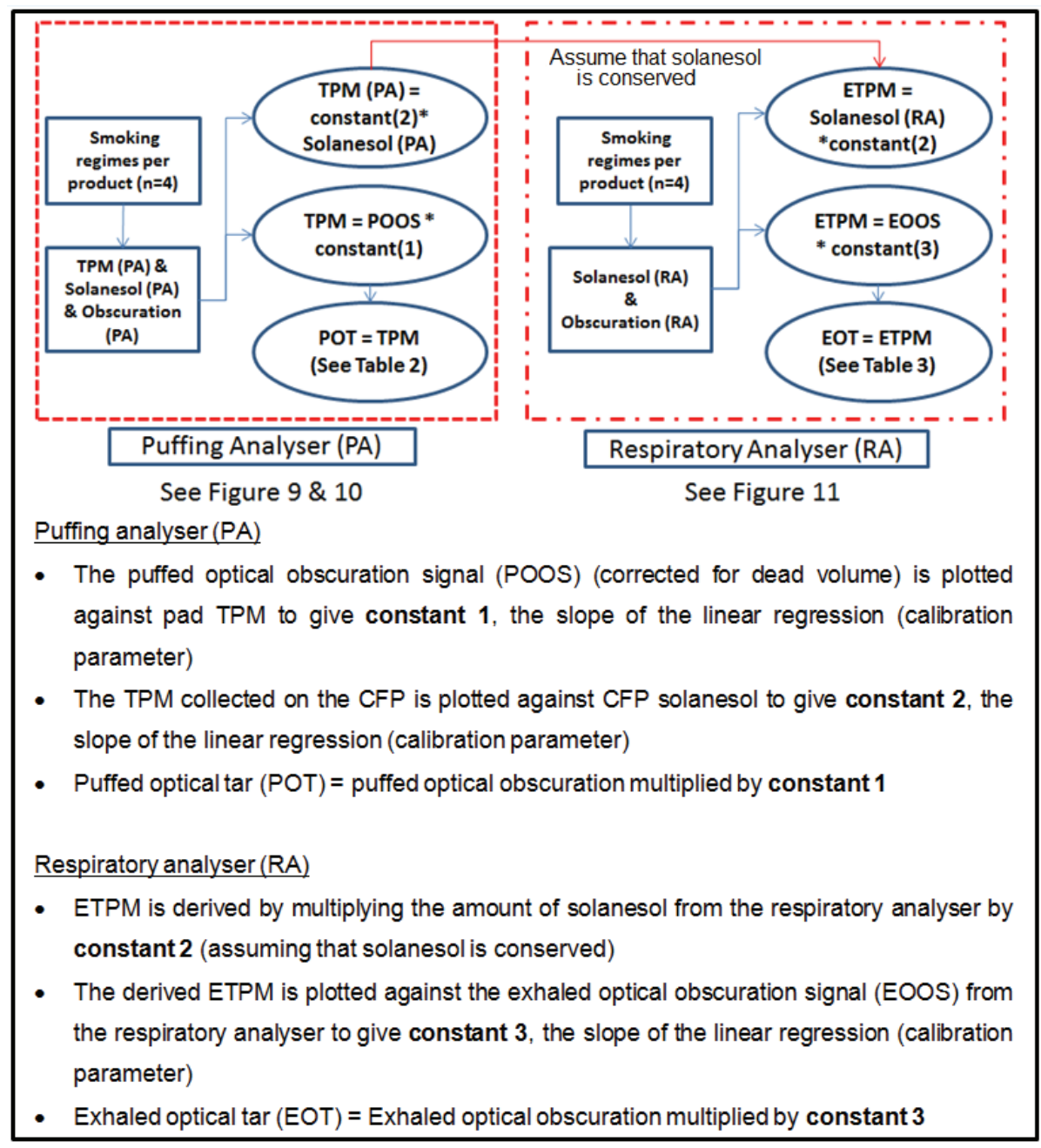

Figure 8. Summary of the optical calibration. 
The puffed optical obscuration signal from the puffing analyser (corrected for dead volume using equation 1, described in the Methodology section) was first calibrated for TPM by comparing the puffed optical obscuration signal for the different calibration regimes to the amount of TPM collected on the CFP. Figure 9 shows an example of this calibration carried out with commercial test cigarettes (ISO $7 \mathrm{mg}$ "tar"). The linear relationship produced a calibration factor of 1.235 (constant 1) with a correlation coefficient $\left(\mathrm{R}^{2}\right)$ of 0.905 .

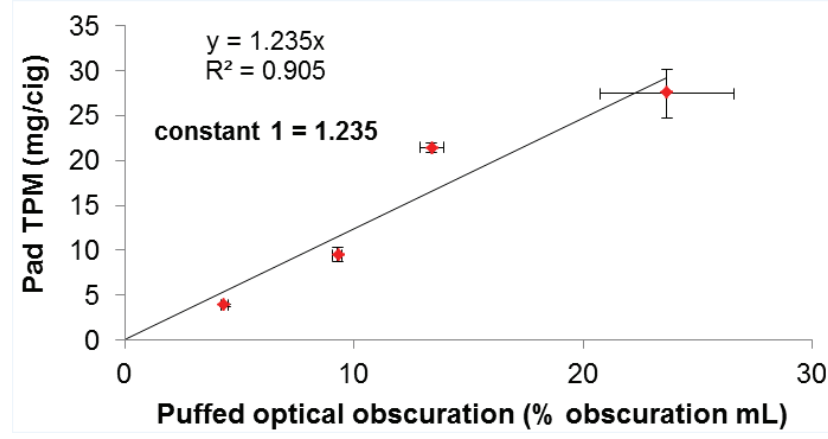

Figure 9. Calibration of puffed optical obscuration signal from the puffing analyser to pad TPM using ISO $7 \mathrm{mg}$ tar cigarettes.

This calibration factor (constant 1) was used to convert the puffed optical obscuration signal into puffed optical "tar" (mg). The TPM on the CFP was also compared to the amount of solanesol that was measured on the CFP in order to produce another linear calibration with a calibration factor of 40.155 (constant 2) and a correlation coefficient $\left(\mathrm{R}^{2}\right)$ of 0.975 (Figure 10).

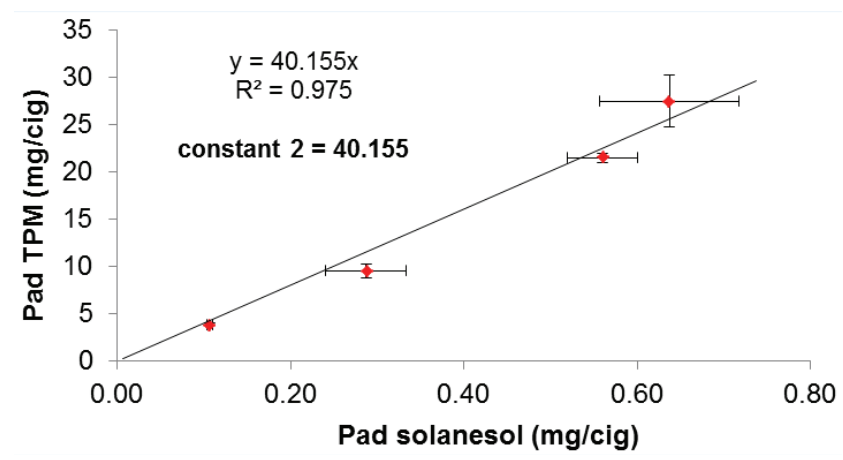

Figure 10. Calibration of pad solanesol versus pad TPM from ISO $7 \mathrm{mg}$ tar cigarettes.

The data from the puffing analyser calibration are reported in Table 2.

The exhaled optical obscuration signal of the respiratory analyser was calibrated against the derived ETPM. As discussed in the Methodology section, the high flow rate (200 L.min ${ }^{-1}$ ) through the exhaled breath sampling system resulted in the loss of semi-volatile components of ETPM collected on the CFP and therefore the value of ETPM must be derived. This study shows that approximately $35 \%$ of the ETPM is lost, which is in agreement with an in-house study
Table 2. Puffing analyser calibration data.

\begin{tabular}{l|c|c|c|c|c}
\hline $\begin{array}{l}\text { Regime } \\
\text { no. }\end{array}$ & $\begin{array}{c}\text { Replicate } \\
\text { no. }\end{array}$ & $\begin{array}{c}\text { Pad TPM } \\
\text { (mg/cig) }\end{array}$ & $\begin{array}{c}\text { Solanesol } \\
\text { on CFP } \\
\text { (mg/cig) }\end{array}$ & $\begin{array}{c}\text { Puffed optical } \\
\text { obscuration } \\
(\% \text { obscu- } \\
\text { ration mL) }\end{array}$ & $\begin{array}{c}\text { Puffed } \\
\text { optical "tar" } \\
(\mathrm{mg})\end{array}$ \\
\hline & 1 & 3.8 & 0.1 & 4.3 & 5.3 \\
1 & 2 & 3.8 & 0.1 & 4.5 & 5.6 \\
& 3 & 4.0 & 0.1 & 4.3 & 5.3 \\
& 1 & 8.8 & 0.2 & 9.0 & 11.2 \\
2 & 2 & 9.5 & 0.3 & 9.4 & 11.6 \\
& 3 & 10.3 & 0.3 & 9.4 & 11.6 \\
& 1 & 22.0 & 0.6 & 14.0 & 17.2 \\
& 2 & 21.4 & 0.6 & 13.0 & 16.0 \\
& 3 & 21.0 & 0.5 & 13.3 & 16.4 \\
& 1 & 26.4 & 0.7 & 25.0 & 30.8 \\
4 & 2 & 30.6 & 0.7 & 25.7 & 31.7 \\
& 3 & 25.4 & 0.5 & 20.3 & 25.1 \\
\hline
\end{tabular}

${ }^{\text {a }}$ Constant 1 used to convert puffed optical obscuration signal into puffed optical "tar".

reporting that approximately $34 \%$ of ETPM, but no solanesol, is lost due to the high flow rates $\left(210 \mathrm{~L} \cdot \mathrm{min}^{-1}\right)$ through the exhaled breath sampling system (unpublished data). Therefore, we assume that solanesol is conserved. Constant 2 was applied to the exhaled optical obscuration calibration for the respiratory analyser to derive an estimated value for ETPM, by multiplying it by the amount of measured solanesol on the CFP [equation 2].

$$
\begin{gathered}
\text { Derived ETPM }(\mathrm{mg} / \mathrm{cig})= \\
\frac{(\text { Measured solanesol on CFP })}{\text { Number of cigarettes }} \times \text { Constant } 2
\end{gathered}
$$

The derived ETPM was correlated against the exhaled optical obscuration signal of the respiratory analyser. Using this derived ETPM assumes that the ratio of TPM to solanesol is consistent for both puffed smoke generated using the A14 smoking syringe driver in the puffing analyser optical calibration and smoke that is exhaled from the mouth cast into the exhaled breath sampling system for respiratory analyser optical calibration. Further studies with humans' exhaled smoke are needed for verification. The respiratory analyser optical calibration demonstrated a strong relationship between the derived ETPM and the exhaled optical obscuration signal of the respiratory analyser, which produced a linear calibration with a calibration factor of 0.366 (constant 3 ) and a correlation coefficient $\left(\mathrm{R}^{2}\right)$ of 0.979 (Figure 11).

Constant 3 was used to convert the exhaled optical obscuration signal into exhaled optical "tar" (mg). The data from the respiratory analyser calibration are reported in Table 3 . 


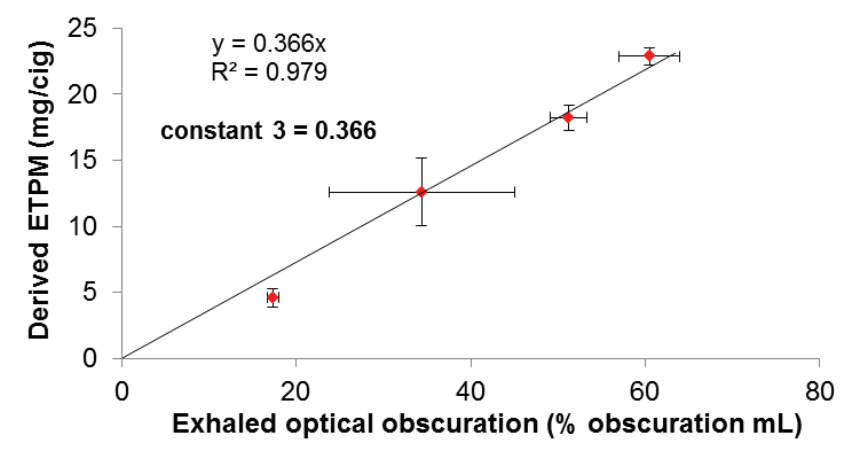

Figure 11. Calibration of exhaled optical obscuration signal from the respiratory analyser to derived ETPM using ISO $7 \mathrm{mg}$ tar cigarettes.

\section{Optical obscuration validation results}

For the optical obscuration validation, ANOVA was used to assess the unit-to-unit and day-to-day effect on puffed and exhaled optical obscuration. There was no significant difference among the SBS units in puffed and exhaled optical obscuration measurements $(P=0.303$ and $P=0.288$, respectively). In addition, there was no significant day-to-day effect on puffed and exhaled optical obscuration measurements $(P=0.094$ and $P=0.214$, respectively). The statistical analysis showed that the SBS units operated consistently from unit-to-unit and day-today, verifying their robustness for use in optical measurements of smoke.

\section{Smoking Behaviour System in practice}

In a "real-life" smoking situation, to capture the smoking cycle, a smoker holds the puffing analyser shown in Figure 1, by the hand grip of the holder, and puffs on the smoking article through the puffing analyser. Following the puff, the puffing analyser is removed from the mouth and the smoker holds the smoke in their mouth. The smoker will then bring the respiratory analyser up to their mouth, holding it by its hand grip. The smoker then inhales and exhales through the respiratory analyser as part of their normal smoking behaviour. After the smoker removes the respiratory analyser from their mouth, and repeats the whole smoking cycle process through the puffing and respiratory analysers. Preliminary field data from a study measuring regional lung deposition (44) show that a typical smoking cycle consists of a sufficiently long mouth hold duration to allow switching between the puffing and respiratory analysers.

\section{CONCLUSIONS}

The SBS described in this paper successfully combines puffing and respiratory devices into a handheld easy-to-use system that provides a means to measure and record the real-time flow and duration profile of puffing, mouth hold, post-puff inhalation, breath hold and exhalation topography, thereby capturing the complete smoking cycle at a 25 $\mathrm{Hz}$ resolution. The measurements are time-aligned such that each one can be considered in isolation or as part of the whole smoking cycle.

The puffing and respiratory analysers have been calibrated and operated between flow rates of $0-7$ L. $\mathrm{min}^{-1}$ and 0-50 L. $\mathrm{min}^{-1}$, respectively. These are ranges that are typically encountered during the human smoking cycle. The volumes measured by the puffing and respiratory analysers met the design specification and tolerance limits of $\pm 2 \%$ and $\pm 5 \%$, respectively.

The SBS is distinct from typical puff or respiratory profilers because it provides real-time puffed and exhaled optical obscuration profiles of the aerosol, and thus an indirect quantification of "tar" from puffed and exhaled cigarette smoke. The optical obscuration measurements showed no statistical difference either among SBS units or in day-to-day variation, demonstrating the robustness of the SBS for use in optical measurements of smoke in combination with topography measurements.

Table 3. Respiratory analyser calibration data.

\begin{tabular}{|c|c|c|c|c|c|c|}
\hline Regime no. & Replicate no. & $\begin{array}{l}\text { Measured ETPM } \\
(\mathrm{mg} / \mathrm{cig})\end{array}$ & $\begin{array}{c}\text { Measured solanesol } \\
\text { on CFP }(\mathrm{mg} / \mathrm{cig})\end{array}$ & $\begin{array}{l}\text { Derived ETPM } \\
\quad(\mathrm{mg} / \mathrm{cig})^{a}\end{array}$ & $\begin{array}{c}\text { Exhaled optical } \\
\text { obscuration } \\
\text { (\% obscuration } \mathrm{mL} \text { ) }\end{array}$ & $\begin{array}{l}\text { Exhaled optical "tar" } \\
(\mathrm{mg})^{\mathrm{a}}\end{array}$ \\
\hline \multirow{3}{*}{1} & 1 & 2.7 & 0.11 & 4.41 & 17.1 & 6.3 \\
\hline & 2 & 3.2 & 0.10 & 4.03 & 16.8 & 6.1 \\
\hline & 3 & 3.3 & 0.13 & 5.38 & 18.1 & 6.6 \\
\hline \multirow{3}{*}{2} & 1 & 9.8 & 0.39 & 15.63 & 42.9 & 15.7 \\
\hline & 2 & 7.5 & 0.29 & 11.49 & 22.5 & 8.2 \\
\hline & 3 & 6.8 & 0.27 & 10.82 & 37.8 & 13.8 \\
\hline \multirow{3}{*}{3} & 1 & 11.4 & 0.44 & 17.79 & 49.6 & 18.1 \\
\hline & 2 & 11.8 & 0.44 & 17.70 & 50.5 & 18.5 \\
\hline & 3 & 12.9 & 0.48 & 19.42 & 53.5 & 19.6 \\
\hline \multirow{3}{*}{4} & 1 & 14.3 & 0.57 & 23.06 & 60.8 & 22.2 \\
\hline & 2 & 16.2 & 0.56 & 22.30 & 63.8 & 23.3 \\
\hline & 3 & 13.4 & 0.59 & 23.54 & 56.9 & 20.8 \\
\hline
\end{tabular}

${ }^{\text {a }}$ Constant 2 used to derive ETPM from solanesol measurement (equation 2).

${ }^{\mathrm{b}}$ Constant 3 used to convert the exhaled optical obscuration signal into exhaled optical "tar", (equivalent to derived ETPM). 
A limitation of the study was that the puffed smoke was not conditioned to reflect the effect of the high humidity in the human lung and hygroscopic growth of the smoke particles; as a result, the present measurements may not be fully representative of exhaled smoke. Further studies with human exhaled smoke are required for verification.

\section{ACKNOWLEDGEMENTS}

BAT acknowledge Mr. N. Oakes and Mr. T. Dale (formerly C-Matic Systems Ltd.) for support with the design and construction of the SBS data acquisition transfer unit. The authors thank Graham Errington and John McAughey at British American Tobacco for invaluable guidance on statistics and expertise in aerosol science, respectively; and Jason Adamson for contributing to the figures in this manuscript.

\section{AUTHOR CONTRIBUTIONS}

Carl A. Vas performed the experimental work, conducted the data analysis and statistics and authored the manuscript. Caner Ü. Yurteri reviewed the data collection and data analysis and co-authored the manuscript. Colin J. Dickens and Krishna Prasad provided scientific support and reviewed the manuscript. All authors read and approved the final manuscript.

\section{REFERENCES}

1. Leach, C.L., P.J. Kuehl, R. Chand, L. Ketai, J.P. Norenberg, and J.D. McDonald: Characterization of Respiratory Deposition of Fluticasone-Salmeterol Hydrofluoroalkane-134a and Hydrofluoroalkane-134a Beclomethasone in Asthmatic Patients; Ann. Allergy Asthma Immunol. 108 (2012) 195-200.

2. Hickey, A.J.: Pharmaceutical Inhalation Aerosol Technology; CRC Press, Boca Raton, FL, USA, second edition, 2003.

3. Dickens, C., C. McGrath, N. Warren, P. Biggs, and J. McAughey: Puffing and Inhalation Behaviour in Cigarette Smoking: Implications for Particle Diameter and Dose; J. Phys. Conf. Ser. 151 (2009) 012019, available at www.http://iopscience.iop.org/1742-6596/ 151/1/012019/pdf/1742-6596_151_1_012019.pdf (accessed February 2015).

4. Hofmann, W.: Modelling Inhaled Particle Deposition in the Human Lung - A Review; J. Aerosol Sci. 42 (2011) 693-724.

5. Yeh, H.C., R.F. Phalen, and O.G. Raabe: Factors Influencing the Deposition of Inhaled Particles; Environ. Health Perspect. 15 (1976) 147-156.

6. St. Charles, F.K., J. McAughey, and C.J. Shepperd: Methodologies for the Quantitative Estimation of Toxicant Dose to Cigarette Smokers Using Physical, Chemical and Bioanalytical Data; Inhal. Toxicol. 25 (2013) 383-397.

7. Dixon, M. and R. Baker: Influence of Cigarette Design on Human Smoking Behaviour and Sensory Responses;
Recent Adv. Tob. Sci. 29 (2003) 77-98.

8. Gregg, E., T. Bachmann, R. Bito, X. Cahours, M. McEwan, P. Nelson, K. Prasad, G. Scherer, and M. Stiles: Assessing Smoking Behaviour and Tobacco Smoke Exposure: Definition and Methods; Beitr. Tabakforsch. Int. 25 (2013) 685-699.

9. Slayford, S.J. and B.E. Frost: A Device to Measure a Smoker's Puffing Topography and Real-Time Puff-byPuff “Tar” Delivery; Beitr. Tabakforsch. Int. 26 (2014) 74-84.

10. O’Connor, R.J., R.L. Ashare, K.M. Cummings, and L.W. Hawk Jr: Comparing Smoking Behaviors and Exposures From Flavored and Unflavored Cigarettes; Addict. Behav. 32 (2007) 869-874.

11. Lee, E.M., J.L. Malson, A.J. Waters, E.T. Moolchan, and W.B. Pickworth: Smoking Topography: Reliability and Validity in Dependent Smokers; Nicotine Tob. Res. 5 (2003) 673-679.

12. Shahab, L., D. Hammond, R.J. O'Connor, M. Cummings, R. Borland, B. King, and A. McNeill: The Reliability and Validity of Self-Reported Puffing Behavior: Evidence from a Cross-National Study; Nicotine Tob. Res. 10 (2008) 867-874.

13. Blank, M.D., S. Disharoon, and T. Eissenberg: Comparison of Methods for Measurement of Smoking Behavior: Mouthpiece-Based Computerized Devices Versus Direct Observation; Nicotine Tob. Res. 11 (2009) 896-903.

14. Tidey, J.W., D.J. Rohsenow, G.B. Kaplan, R.M. Swift, and C.G. AhnAllen: Separate and Combined Effects of Very Low Nicotine Cigarettes and Nicotine Replacement in Smokers with Schizophrenia and Controls; Nicotine Tob. Res. 15 (2013) 121-129.

15. Perkins, K.A., J.L. Karelitz, G.E. Giedgowd and C.A. Conklin: The Reliability of Puff Topography and Subjective Responses During Ad Lib Smoking of a Single Cigarette; Nicotine Tob. Res. 14 (2012) 490-494.

16. Donny, E.C. and M. Jones: Prolonged Exposure to Denicotinized Cigarettes With or Without Transdermal Nicotine; Drug Alcohol Depend. 104 (2009) 23-33.

17. Van Amsterdam, J., A. Sleijffers, P. van Spiegel, R. Blom, M. Witte, J. van de Kassteele, M. Blokland, P. Steerenberg, and A. Opperhuizen: Effect of Ammonia in Cigarette Tobacco on Nicotine Absorption in Human Smokers; Food Chem. Toxicol. 49 (2011) 3025-3030.

18. Oldham, M.J., S.E. Plunkett, M.T. Fisher, K.H. Shafer, and M.J. Morton: Laboratory Evaluation of the CReSSmicro $^{\text {TM }}$ Portable Topography Device: Implications for Clinical Research; Beitr. Tabakforsch. Int. 26 (2014) 19-25.

19. Bernstein, D.M.: A Review of the Influence of Particle Size, Puff Volume and Inhalation Pattern on the Deposition of Cigarette Smoke Particles in the Respiratory Tract; Inhal. Toxicol. 16 (2004) 675-689.

20. St. Charles, F.K., G.R. Krautter, and D.C. Mariner: Post-Puff Respiration Measures on Smokers of Different Tar Yield Cigarettes; Inhal. Toxicol. 21 (2009) 712-718.

21. Adams, L., C. Lee, R. Rawbone, and A. Guz: Patterns of Smoking: Measurement and Variability in Asymptomatic Smokers; Clin. Sci. (London) 65 (1983) 383-392. 
22. Guillerm, R. and E. Radziszeski: Analysis of Smoking Pattern Including Intake of Carbon Monoxide and Influences of Changes in Cigarette Design; in: Smoking Behaviour: Physiological and Psychological Influences; edited by R.E. Thornton, Churchill Livingstone, Edinburgh, UK, 1978, pp. 361-370.

23. Hee, J., F. Callais, I. Momas, A.M. Laurent, S. Min, P. Molinier, M. Chastagnier, J.R. Claude, and B. Festy: Smokers' Behaviour and Exposure According to Cigarette Yield and Smoking Experience; Pharmacol. Biochem. Behav. 52 (1995) 195-203.

24. McBride, M.J., A.R. Guyatt, A.J. Kirkham, and G. Cumming: Assessment of Smoking Behaviour and Ventilation With Cigarettes of Differing Nicotine Yields; Clin. Sci. (London) 67 (1984) 619-631.

25. Nil, R., R. Buzzi, and K. Bättig: Effects of Different Cigarette Smoke Yields on Puffing and Inhalation: Is the Measurement of Inhalation Volumes Relevant for Smoke Absorption?; Pharmacol. Biochem. Behav. 24 (1986) 587-595.

26. Nil, R., P.P. Woodson, and K. Bättig: Smoking Behaviour and Personality Patterns of Smokers With Low and High CO Absorption; Clin. Sci. 71 (1986) 595-603.

27. Rawbone, R.G., K. Murphy, M.E. Tate, and S.J. Kane: The Analysis of Smoking Parameters: Inhalation and Absorption of Tobacco Smoke in Studies of Human Smoking Behaviour; in: Smoking Behaviour: Physiological and Psychological Influences, edited by R.E. Thornton, Churchill Livingstone, Edinburgh, UK, 1978, pp.171-194.

28. Robinson, J.H., W.S. Pritchard, and R.A. Davis: Psychopharmacological Effects of Smoking a Cigarette With Typical "Tar" and Carbon Monoxide Yields but Minimal Nicotine; Psychopharmacology (Berl.) 108 (1992) 466-472.

29. Tobin, M.J. and M.A. Sackner: Monitoring Smoking Patterns of Low and High Tar Cigarettes With Inductive Plethysmography; Am. Rev. Respir. Dis. 126 (1982) 258-264.

30. Woodman, G., S.P. Newman, D. Pavia and S.W. Clarke: Inhaled Smoke Volume, Puffing Indices and Carbon Monoxide Uptake in Asymptomatic Cigarette Smokers; Clin. Sci. 71 (1986) 421-427.

31. Woodson., P.P. and R.R. Griffiths: Control of Cigarette Smoking Topography: Smoke Filtration and Draw Resistance; Behav. Pharmacol. 3 (1992) 99-111.

32. Zacny, J.P. and M.L. Stitzer: Cigarette BrandSwitching: Effects on Smoke Exposure and Smoking Behaviour; J. Pharmacol. Exp. Ther. 246 (1988) 619-627.

33. Zacny, J.P., M.L. Stitzer, and J.E. Yingling: Cigarette Filter Vent Blocking: Effects on Smoking Topography and Carbon Monoxide Exposure; Pharmacol. Biochem. Behav. 25 (1986) 1245-1252.

34. Hammond, D., G.T. Fong, K.M. Cummings, R.J. O’Connor, G.A. Giovino, and A. McNeill: Cigarette Yields and Human Exposure: A Comparison of Alternative Testing Regimens; Cancer Epidemiol. Biomarkers Prev. 15 (2006) 1495-1501.

35. McAughey, J. and C. McGrath: Measurement Tools for Tobacco Smoke Deposition in Human Lung; Poster presented at Drug Delivery to the Lungs DDL18, Edinburgh, UK, December 2007.

36. International Organisation for Standardization (ISO): ISO 20773:2013. Cigarettes - Determination of Nicotine-Free Dry Particulate Matter and Nicotine in Sidestream Smoke - Method Using a Routine Analytical Linear Smoking Machine Equipped With a Fishtail Chimney; ISO, Geneva, Switzerland, 2013.

37. Nelson P.R., F.W. Conrad, S.P. Kelly, K.C. Maiolo, J.D. Richardson, and M.W. Ogden: Composition of Environmental Tobacco Smoke (ETS) From International Cigarettes and Determination of ETSRSP: Particulate Marker Ratios; Environ. Int. 23 (1997) 47-52.

38. Warrington, P., C. McGrath, J. Perkins, K. Reavell, and C. Dickens: An Instrument to Simulate Puffing, Inhaling and Exhaling Cigarette Smoke; Presentation 8P293 at European Aerosol Conference, Manchester, 2011, available at: http://www.pipistrelle-test.com/ groupms/sites/BAT_7AWFH3.nsf/vwPagesWebLive/ DO8LBGWU/\$FILE/EAC\%20Poster\%20v6.pdf?ope nelement (accessed January 2015).

39. Cabot, R., C. McGrath, P. Biggs, and C. Dickens: Development of an Anatomically Correct Segmented Model of the Human Mouth for Deposition Studies of the Particle and Vapour Phase of Tobacco Smoke During Inhalation; Presentation 7D2 at European Aerosol Conference, Manchester, 2011, available at: http://www.bat.com/groupms/sites/BAT_9GVJXS.ns f/vwPagesWebLive/DO8LEE6X/\$FILE/EAC\%20Pre sentation $\% 20$ V2\%20[Read-Only].pdf?openelement (accessed January 2015).

40. Dickens, C., C. McGrath, P. Biggs, J. Perkins, R. Cabot, and J. McAughey: Tools for Measuring Tobacco Smoke Dose in the Human Lung; Poster presented at Lhasa Symposium, Leeds, 2010, available at: http://www.bat.com/groupms/sites/BAT 9GVJXS.nsf/vwPagesWebLive/DO8AFJLL/\$FILE/ dosimetry\%20tools.pdf?openelement (accessed January 2015).

41. Rodgman, A. and T.A. Perfetti: The Chemical Components of Tobacco and Tobacco Smoke, second edition, CRC Press, Boca Raton, FL, 2013, pp. 118-119.

42. Pankow, J.F. and W.E. Asher: SIMPOL.1: A Simple Group Contribution Method for Predicting Vapor Pressures and Enthalpies of Vaporization of Multifunctional Organic Compounds; Atmos. Chem. Phys. 8 (2008) 2773-2796.

43. ChemSpider: Solanesol $\left|\mathrm{C}_{45} \mathrm{H}_{74} \mathrm{O}\right|$; Royal Society of Chemistry, London, 2014, available at: http:// www.chemspider.com/Chemical-Structure. 4585196.html (accessed January 2015).

44. Yurteri, C.U., C.J. Dickens, C.M. McGrath, R.A. Cabot, J. Hawke, J.W. Perkins, and J.J. McAughey: Estimating the Regional Deposition of Tobacco Smoke in the Human Respiratory System; Presentation at Advancing Aerosol Dosimetry Research Conference, Irvine California, USA, 2014, available at: http://www.bat.com/groupms/sites/BAT_9GVJXS.ns f/vwPagesWebLive/DO9Q5HPS/\$FILE/AADR_CY 2014.pdf?openelement (accessed January 2015). 
Corresponding Author:

Carl A. Vas

Group Research \& Development

British American Tobacco

Regents Park Road, Southampton

SO15 8TL, United Kingdom

E-mail: Carl_Vas@bat.com 